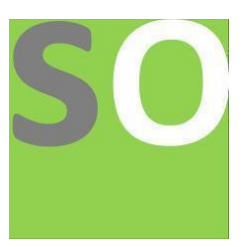

Article title: Awareness of Pregnant Women Registered with Federal Medical Centre, Makurdi on the Risk Factors of Obstetric Emergencies

Authors: Joy Dzever [1], Olusegun Ojo[2], Suleiyol Charity Abatur[3]

Affiliations: Department of Pharmacy, Federal Medical Centre Makurdi, Benue State - Nigeria[1], Department of Pharmacy Information, Research and Training, Federal Medical Centre, Makurdi, Benue State - Nigeria[2]

Orcid ids: 0000-0002-2750-6779[1]

Contact e-mail: dzeverjoy@yahoo.com

License information: This work has been published open access under Creative Commons Attribution License http://creativecommons.org/licenses/by/4.0/, which permits unrestricted use, distribution, and reproduction in any medium, provided the original work is properly cited. Conditions, terms of use and publishing policy can be found at https://www.scienceopen.com/.

Preprint statement: This article is a preprint and has not been peer-reviewed, under consideration and submitted to ScienceOpen Preprints for open peer review.

Funder: Self-funding

DOI: 10.14293/S2199-1006.1.SOR-.PPTNJUZ.v1

Preprint first posted online: 08 November 2021

Keywords: Obstetric emergencies, risk factors, maternal and child mortality, awareness 


\section{AWARENESS OF PREGNANT WOMEN REGISTERED WITH FEDERAL MEDICAL CENTRE, MAKURDI ON THE RISK FACTORS OF OBSTETRIC EMERGENCIES}




\begin{abstract}
Obstetric emergencies are the leading cause of maternal and child mortality worldwide. According to WHO, about $15 \%$ of all pregnant women will develop obstetric emergencies that will require special skills to manage. A Nigerian woman has a 1 in 22 lifetime risk of dying during pregnancy, childbirth or postpartum/post-abortion whereas most other developed countries have a risk of 1 in 4900. With figures so high, there is need for prompt response to arrest the problem. A good knowledge/awareness of pregnant women on the predisposing risk factors for occurrence of obstetric emergencies better equips them with appropriate steps to take in preventing the occurrence of such.

In this study, the awareness of pregnant women on the risk factors of obstetric emergencies was assessed. Just about $37 \%$ of the women knew the concept of obstetric emergencies but when asked the specific types, a good number were aware of all the types. The most popular type was postpartum hemorrhage with $43.5 \%$ knowledge. The risk factors most recognized included poor antenatal care, age, infection, drugs and alcohol. $96 \%$ of the population however did not think they were at risk of developing any obstetric emergency.
\end{abstract}

Key words: Obstetric emergencies, risk factors, maternal and child mortality, awareness. 


\section{CHAPTER ONE}

\subsection{INTRODUCTION AND LITERATURE REVIEW}

\subsection{INTRODUCTION}

Pregnancy is a thing of joy for most women! While most pregnancies and childbirths are uneventful and normal, about $15 \%$ of all pregnant women will develop a potentially life threatening complication requiring skilled care/ intervention to survive (WHO).

ALL pregnancies are at risk of developing obstetric emergencies! These emergencies are much more delicate owing to the fact that at least two patients; the mother and her baby (ies) are involved. Obstetric emergencies are the leading cause of maternal and child mortality worldwide, especially in developing countries where poverty, lack of antenatal care, literacy, poor transport and equipment/ staffing make them more prevalent (Olonade et al 2019). The survival of a woman experiencing an obstetric emergency is determined by the amount of time taken to deliver care and the level and quality of care provided (WHO, 2017).

\subsection{LITERATURE REVIEW}

Obstetrics is the field of study which concentrates on pregnancy, childbirth and the postpartum period. An emergency is a serious, often dangerous situation which develops unexpectedly and requires immediate attention to prevent loss of life. An obstetric emergency is therefore an unexpected, potentially dangerous situation which develops during pregnancy, childbirth or shortly after the birth of a child.

\subsection{TYPES OF OBSTETRIC EMERGENCIES}

i. Hypertensive conditions in pregnancy

\section{- Pre-eclampsia:}

Pre-eclampsia is the presence of hypertension with a diastolic arterial pressure of $\geq 90 \mathrm{mmHg}$ and/or systolic arterial pressure of $\geq 140 \mathrm{mmHg}$ that develops after 20 weeks of gestation in association with proteinuria ( $\geq 0.3 \mathrm{~g}$ in a 24 hour specimen). A global incidence rate of $4.6 \%$ was recorded for pre-eclampsia by Abalos et al, 2013 in a review involving 40 countries with 39 million women. In developing countries, the prevalence rate of pre-eclampsia ranges from $1.8 \%$ to $16.7 \%$ (Osungbade and Ige, 2011).

The risk factors for development of pre-eclampsia include a previous history of pre-eclampsia, pre-existing hypertension, chronic kidney disease, insulin dependent diabetes, etc (English et al, 2015).

\section{- Eclampsia}


Eclampsia is the presence of seizures and/or coma in a woman suffering from preeclampsia/ not caused by coincidental neurologic disease. The symptoms of eclampsia may start before, during or after childbirth until the fourth week postpartum. It occurs typically during or after the $20^{\text {th }}$ week of gestation or within 48 hours postpartum (Micheal Ross, 2019).

The risk factors for eclampsia include: family history of eclampsia or preeclampsia, previous eclampsia or pre-eclampsia, teen pregnancy, women $>35$ years, chronic hypertension, gestational diabetes, multifetal gestations, etc.

ii. Antepartum Hemorrhage

- Ectopic pregnancy

Ectopic pregnancy results when the fertilized ovum implants in tissues rather than the lining of the uterus, ultimately leading death of the fetus. This condition can be life threatening if it is not diagnosed and treated early enough. About $95 \%$ of ectopic pregnancies occur in the fallopian tube (Ali et al, 2019). Other sites include ovary, cervix and the abdomen.

- Abruptio placentae

- Placenta previa

\section{iii. Postpartum hemorrhage}

The World Health Organisation defines postpartum hemorrhage as blood loss greater than $500 \mathrm{~mL}$ within 24 hours after birth, and severe primary postpartum hemorrhage as blood loss greater than $1000 \mathrm{~mL}$ within 24 hours after birth. It is the leading cause of maternal mortality, accounting for about 35\% of all maternal deaths (Paul Ashigbie, 2013).

The risk factors for postpartum hemorrhage include antepartum hemorrhage, prolonged labor, maternal obesity, augmented labor, fetal macrosomia, multifetal gestation, preeclampsia, etc. women with risk factors are more prone to postpartum hemorrhage however, $20 \%$ of postpartum hemorrhage occurs in women with no risk factors (Evensen et al, 2017).

iv. Obstetric infections

- Septic abortion

- Obstetric sepsis and septic shock

v. Cardiorespiratory arrest in pregnancy

vi. Preterm labour and delivery

\subsection{RISK FACTORS FOR OBSTETRIC EMERGENCIES}

- Age: 
Adolescents who make up 13\% of all pregnancies have an increased incidence of preeclampsia, preterm labor and anemia. This is usually due to neglect of prenatal care, smoking and alcohol and higher rates of STDs. Women $>35$ experience increased pre- eclampsia, gestational diabetes, dysfunctional labor, still birth, low birth weight, abruption placenta and placenta previa (Blomberg et al, 2014). This is also because women in this age group are more likely to have pre-existing conditions like diabetes and hypertension. Babies born of women older than 35 years are also at a higher risk of fetal chromosomal abnormalities.

- Poor antenatal care:

About 69\% of pregnant women in Africa have at least one antenatal visit (WHO). At least four visits are however required to achieve the full life-saving potential of antenatal care (Lincetto et al,). The essential interventions of antenatal care include; identification and management of obstetric complications like pre-eclampsia and identification and management of infections like HIV, Syphilis and other STDs. Failure to attend antenatal or insufficient attendances places the pregnant mother at a high risk of developing obstetric emergencies and a higher chance of obstetric emergencies developed to result in fatal consequences.

\section{- Physical and social characteristics}

Pregnant women who are underweight (BMI $<19.8 \mathrm{~kg} / \mathrm{m}^{2}$ ) before pregnancy are predisposed to having underweight neonates $(<2.5 \mathrm{~kg})$. Overweight and obese women are at high risk of pre-eclampsia, gestational diabetes, fetal macrosomia, miscarriage and congenital malformations when the eventually get pregnant.

Shorter women $(<152 \mathrm{~cm})$ are more likely to have a small pelvis which can lead to dystocia. They are also more prone to preterm labour (Artal-Mittelmark, 2019)

- Previous history of OE:

A previous preterm delivery due to preterm labour of a neonate weighing less than $1.5 \mathrm{~kg}$ poses a $50 \%$ risk preterm delivery in the next pregnancy (Artal-Mittelmark, 2019). Women with previous preterm delivery should be monitored every 2 weeks after 20 weeks of pregnancy.

A previous stillbirth also increases the risk of fetal death in subsequent pregnancies. The degree to which the risk increases depends on the cause of the previous stillbirth.

\section{- Exposure to teratogens:}

Infections (like herpes simplex, viral hepatitis, Syphilis, etc) and drugs/substances (including alcohol, tobacco, cocaine and some prescription medicines like antidepressants) are the common teratogens that pregnant women are often exposed to during pregnancy. 
- Existing medical conditions including:

- Hypertension

○ Diabetes

- Sexually transmitted diseases

- Genital tract abnormalities

\subsection{STATEMENT OF THE PROBLEM}

About $15 \%$ of all pregnant women will develop life threatening obstetric emergencies that will require special skills to manage (WHO). The key to managing all emergencies is early detection of these disorders during pregnancy which prevents severe morbidity and mortality through prompt management (Chahabra S, 2017). Nigeria alone accounts for nearly $20 \%$ of all global maternal deaths with an estimated 600, 000 maternal deaths between 2005 and 2015 (WHO). As at 2015, the maternal mortality ratio for Nigeria was estimated to be 800 deaths per 100, 000 live births compared to a total 1700 in 46 most developed countries (WHO). The World Health Organization also posits that a Nigerian woman has a 1 in 22 lifetime risk of dying during pregnancy, childbirth or postpartum/post-abortion while in most other developed countries the risk is 1 in 4900. These figures are alarmingly high, requiring that adequate measures be put in place to arrest the situation. An awareness/knowledge of pregnant women on the risk factors that predispose them to developing these emergencies will ensure that they report to the hospital early enough for prompt attention to be administered. This will ultimately lead to reduced maternal and child mortality as nearly half of maternal deaths are preventable (Artal-Mittelmark, 2019). This study will assess the level of awareness of pregnant women on the risks that predispose them to obstetric emergencies which often lead to death.

\subsection{AIMS AND OBJECTIVES}

The aim of the study is to establish the level of awareness of pregnant women on the risk factors that could predispose them to developing Obstetric emergencies.

The objectives include:

i. To assess the knowledge of pregnant women about obstetric emergencies.

ii. To assess their knowledge on the risk factors of obstetric emergencies

iii. To assess their attitude towards the occurrence of obstetric emergencies

iv. To assess the level of preventive measures followed by pregnant women to avoid obstetric emergencies.

\section{CHAPTER TWO}




\subsection{METHOD}

\section{$2.1 \quad$ STUDY SETTING}

The study area for the research was the Antenatal clinic of Federal Medical Centre, Makurdi, a tertiary health institution in Benue State.

\subsection{STUDY DESIGN}

This study was a hospital based cross sectional study in which pregnant women registered with the antenatal clinic of the hospital were the respondents. It assessed their level of knowledge on obstetric emergencies, the risks factors for developing obstetric emergencies as well as their attitude towards the occurrence of obstetric emergencies.

\subsection{STUDY POPULATION AND SIZE}

The study population comprised of pregnant women attending the antenatal clinic of Federal Medical Centre, Makurdi. Based on the Cochran formula (Singh and Masuku, 2014) for an unknown population, a total of 139 pregnant women made up the sample size.

\section{$\mathbf{N}=\mathbf{Z}^{2} \mathbf{P}(\mathbf{1}-\mathbf{P})$ \\ $d^{2}$}

where:

$\mathrm{N}=$ the desired sample size

$Z^{2}=3.841$ for $95 \%$ Confidence level

$\mathrm{P}=$ Estimated portion of an attribute present in the population and for this study, Nigeria accounts for about $10 \%$ of global annual maternal mortality $=0.1($ Omo-Aghoja et al, 2010)

$1-\mathrm{P}=$ power of study is $1-0.1=0.9$

$\mathrm{d}^{2}=$ expected precison is $5 \%=0.05^{2}=0.0025$

thus,

$\mathrm{N}=3.841 \times 0.1(0.9)$

0.0025 
$\mathrm{N}=138.276 \approx 139$

The sampling technique was a simple random one in which all pregnant women who picked 'yes' out of a ballot were included. The ballot contained just 139 yeses.

\subsection{DATA COLLECTION}

Data was collected through a face to face interaction with respondents using a questionnaire. The questionnaire contained the following:

i. Sociodemographic profiles including age, educational qualification, marital status, first pregnancy and age at first pregnancy

ii. Knowledge and perception profiles including knowledge of obstetric emergencies, experiences with obstetric emergencies, symptoms experienced, outcomes, risk factors for developing obstetric emergencies and perception on the occurrence of obstetric emergencies.

\subsection{DATA ANALYSIS}

Data from the questionnaires were entered into a Microsoft excel sheet before analysis. The data analysis was carried out using the Statistical Package for Social Sciences (SPSS) software. Frequency and percentage were the major descriptive statistics.

\subsection{ETHICAL CONSIDERATION}

Ethical approval for the study was obtained from the ethical committee of the Federal Medical Centre, Makurdi and taken to the Antenatal Clinic of the hospital before the study commenced. The confidentiality of respondent information was strictly observed as the identity and submissions of respondents were not divulged.

\section{CHAPTER THREE}

\subsection{RESULTS}


Table 1. Respondent demographics $(n=125)$

\begin{tabular}{|c|c|c|}
\hline Age group & Frequency & Percent (\%) \\
\hline$<20$ & 5 & 3.5 \\
\hline $21-30$ & 77 & 61.7 \\
\hline $31-40$ & 39 & 31.3 \\
\hline $41-50$ & 1 & 0.8 \\
\hline Unspecified & 4 & 2.6 \\
\hline \multicolumn{3}{|l|}{ Marital status } \\
\hline Divorced & 52 & 41.7 \\
\hline Married & 61 & 48.7 \\
\hline Single & 8 & 6.1 \\
\hline Widowed & 1 & 0.8 \\
\hline Unspecified & 3 & 2.6 \\
\hline \multicolumn{3}{|l|}{ Education } \\
\hline Secondary & 23 & 18.3 \\
\hline Tertiary & 90 & 72.2 \\
\hline Unspecified & 12 & 9.6 \\
\hline \multicolumn{3}{|l|}{ Occupation } \\
\hline Civil servant & 27 & 21.7 \\
\hline Self-employed & 28 & 22.6 \\
\hline Student & 7 & 5.2 \\
\hline Others & 50 & 40.0 \\
\hline Unspecified & 13 & 10.4 \\
\hline \multicolumn{3}{|l|}{ First pregnancy } \\
\hline Yes & 57 & 45.6 \\
\hline No & 66 & 52.8 \\
\hline Unspecified & 2 & 1.6 \\
\hline Age at first pregnancy & Frequency & Percent $\%$ \\
\hline$<20$ & 6 & 5.2 \\
\hline $21-30$ & 55 & 47.8 \\
\hline $31-40$ & 5 & 4.4 \\
\hline
\end{tabular}


The table above shows that $61.7 \%$ of respondents were between the ages of 21-30 years and $31.3 \%$ between $31-40$ years. $48.7 \%$ of the population married, about $72.2 \%$ had a tertiary education. 53\% of the population had had previous pregnancies with most having their first pregnancy between the ages of 21-30 years.

Table 2. Knowledge of Obstetric Emergencies

Knowledge of obstetric emergencies

$(\mathbf{n}=\mathbf{1 3 9})$

$\begin{array}{lccc}\text { Yes } & 51 & 36.7 & \\ \text { No } & 61 & 43.9 & \\ \text { Not sure } & 27 & 19.4 & \\ & & & \\ \begin{array}{l}\text { Knowledge of specific obstetric } \\ \text { emergencies }\end{array} & \text { Yes } & \text { No } & \text { Not sure } \\ \begin{array}{l}\text { Post partumhaemorrhage } \\ \text { Pre-eclampsia }\end{array} & 50(43.5) & 55(47.8) & 10(8.7) \\ \text { Eclampsia } & 36(31.3) & 70(60.9) & 9(7.9) \\ \text { Ectopic pregnancy } & 36(31.3) & 13(11.3) & 66(57.4) \\ \text { Abruptia placentae } & 56(48.7) & 45(39.1) & 14(12.2) \\ \text { Placenta previa } & 39(33.9) & 59(51.3) & 17(14.7) \\ \text { Septic abortion } & 33(28.7) & 63(54.8) & 19(16.5) \\ \text { Obstetric sepsis } & 29(25.2) & 70(60.9) & 16(13.9) \\ \text { Preterm labour } & 30(26.1) & 69(60.0) & 16(13.9) \\ \end{array}$

The table above shows that just $36.7 \%$ of respondents know what obstetric emergencies are and postpartum hemorrhage (43.5\%), ectopic pregnancy (48.7\%), and preterm labor (45.2\%) are the most known obstetric emergencies.

Table 3. Experience, symptoms and outcome of Obstetric Emergencies

Experience of Obstetric emergencies $\quad$ Yes $\quad$ No $\quad$ Not sure

$(n=115)$ 
Post partumhaemorrhage

Pre-eclampsia

Eclampsia

Ectopic pregnancy

Abruptia placentae

Placenta previa

Septic abortion

Obstetric sepsis

Preterm labour
$11(9.6)$

4 (3.5)

3 (2.6)

$5(4.3)$

$5(4.3)$

$2(1.7)$

2 (1.7)

$5(4.3)$

7 (6.1)
$88(76.5) \quad 16(13.9)$

$84(73.0) \quad 27(23.5)$

$82(71.3) \quad 30(26.1)$

$85(73.9) \quad 25(21.7)$

$83(72.2) \quad 27(23.5)$

$85(73.9) \quad 28(24.4)$

88 (76.5) $25(21.7)$

$83(72.2) \quad 27(23.5)$

88 (76.5) $20(17.4)$

$\begin{array}{lll}\begin{array}{l}\text { Have you experienced symptoms } \\ (\mathbf{n = 1 1 5})\end{array} & \text { Frequency } & \text { Percent } \\ \text { Yes } & 8 & 7.0 \\ \text { No } & 107 & 93.0\end{array}$

Symptoms experienced $(\mathbf{n}=8)$

Abdominal, Pain, Dizziness $\quad 1 \quad 12.5$

$\begin{array}{lll}\text { Bleeding } & 2 & 25.0\end{array}$

Dizziness, Loss of Appetite, Weakness $\quad 1 \quad 12.5$

Headache, Vomiting, Oversleeping $\quad 1 \quad 12.5$

Waist pain, Contractions $\quad 1 \quad 12.5$

$\begin{array}{lll}\text { Weakness } & 1 & 12.5\end{array}$

Waist Pain, Delayed Labour $\quad 1 \quad 12.5$

Outcome (n=8)

Positive $\quad 5 \quad 62.5$

Negative $\quad 3 \quad 37.5$

The table above shows that the most experienced Obstetric emergency among the population is postpartum hemorrhage with symptoms including bleeding, abdominal pain, headache, vomiting, weakness, etc.

Table 4. Risk factors and actions to prevent them

Risk factor $(\mathbf{n}=481)$

Frequency Percent 
$\begin{array}{lll}\text { Age } & 63 & 13.1\end{array}$

$\begin{array}{lll}\text { Poor Antenatal Care } & 65 & 13.5\end{array}$

\begin{tabular}{lll}
\hline $\begin{array}{l}\text { Obstetric emergencies can occur in any } \\
\text { pregnant woman }(n=115)\end{array}$ & Frequency & Percent
\end{tabular}

Witch Craft 21

Infection 63

4.4

Drugs and Alcohol $\quad 61 \quad 12.7$

Physical Exercise $\quad 23 \quad 4.8$

Hypertension $\quad 52 \quad 10.8$

$\begin{array}{lll}\text { Sex } & 16 & 3.3\end{array}$

$\begin{array}{lll}\text { Diabetes } & 37 & 7.7\end{array}$

Previous Obstetric Emergency $\quad 34 \quad 7.1$

$\begin{array}{lll}\text { Ignorance } & 45 & 9.3\end{array}$

$\begin{array}{lll}\text { Stress } & 1 & 0.2\end{array}$

DO YOU HAVE ANY RISK $(\mathbf{n}=130)$

No Risk

$125 \quad 96.2$

Infection

Prolonged Labour

Stress

$3 \quad 2.3$

10.8

$1 \quad 0.8$

\section{ACTIONS TO PREVENT OCCURRENCE OF EMERGENCY $(\mathbf{n}=\mathbf{1 1 1})$}

Informed Physician $\quad 37 \quad 33.3$

Informed Pastor $\quad 11 \quad 10.0$

$\begin{array}{lll}\text { Prayers } & 10 & 9.0\end{array}$

$\begin{array}{lll}\text { Informed Nurses } & 23 & 20.7\end{array}$

Hope It Doesn't Occur $\quad 12 \quad 10.8$

God Forbid! Covered by The Blood Of Jesus $\quad 17 \quad 15.3$

Regular ANC Attendance $\quad 1 \quad 0.9$

In the table above, the most know risk factors are poor antenatal care (13.5\%), age (13.1\%) and infection (13.1\%). 96.2\% of the population did not think they were at risk of developing Obstetric emergencies. 


\begin{tabular}{lll}
\hline True & 76 & 66.1 \\
False & 16 & 13.9 \\
Uncertain & 23 & 20.0 \\
& & \\
It's possible for me to develop obstetric & & \\
emergency (n=115) & & \\
True & 67 & 58.3 \\
False & 22 & 19.1 \\
Uncertain & 26 & 22.6 \\
If I notice obstetric emergency & & \\
I would? (n=127) & & \\
Observe for some days & 29 & 22.8 \\
Inform Doctor immediately & 65 & 51.2 \\
Inform Pastor & 9 & 7.1 \\
Pray and Hope it goes away & 20 & 15.7 \\
Ignore Symptoms & 4 & 3.2 \\
\hline
\end{tabular}

\section{Table 5. Attitude and perception}

In the table above, $66.1 \%$ knew that obstetric emergencies could occur in all pregnant women and 58.3\% thought it was possible to occur in their pregnancy. 51.2\% indicated that they would inform their doctor immediately.

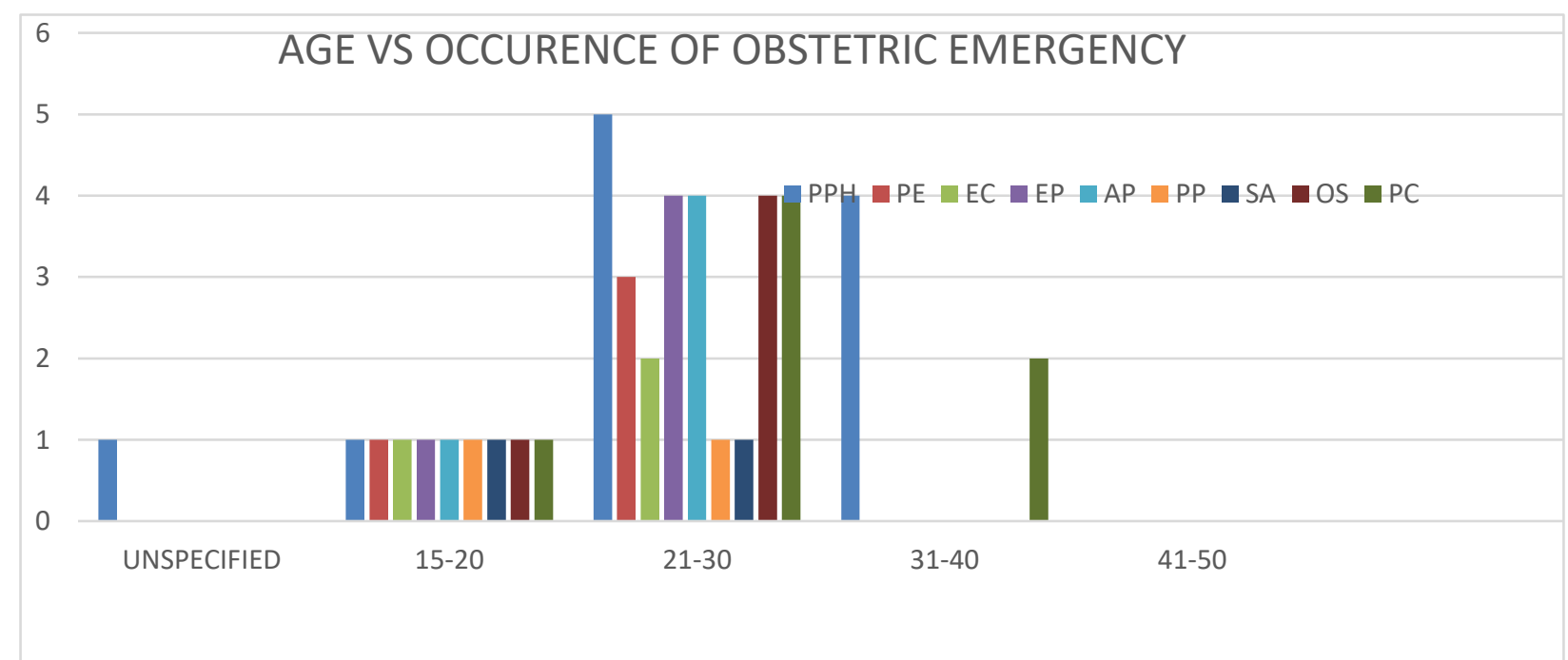

Figure 1. A chart showing the relationship between Age and the occurrence of Obstetric emergencies.

CHAPTER FOUR 


\subsection{DISCUSSION AND CONCLUSION}

\subsection{DISCUSSION}

The best age for pregnancy with less risks of complications is between 21-30 years (Bellieni, 2016) and from the results of the study, the majority of the population fell between the 21-30 years age group, an indication that most of the respondents had less risk of developing emergencies triggered by age. The married population was slightly higher than the divorced population. Marriage is generally associated with improved pregnancy outcomes according to Barr and Marugg, 2019, as such the risk of maternal deaths is greatly reduced in women who are married. This may most likely be because in marriage, the pregnant woman can get the help needed from her spouse and when emergencies occur, there is prompt response. $72.2 \%$ of the pregnant women had had a tertiary education which places them in a better and more enlightened position to be aware of the complications that arise in pregnancy and as such be better equipped to manage them properly this is in agreement with a publication by Ketema et al, 2020 that maternal education has a positive effect on birth preparedness and complication readiness.

About half of the population had been pregnant before with the larger population having their first pregnancy between 21-30 years. Just about $4 \%$ of the population had their first pregnancy between 31-40 years. This is the age group with a high risk for the occurrence of obstetric emergencies especially pre-eclampsia, eclampsia, still births and preterm labour.

Only $37 \%$ of the pregnant women had heard about the concept of obstetric emergencies. This result was quite poor considering that the main stay for the proper management of obstetric emergencies is the early detection of the conditions (Chahabra S, 2017). More than half the population had never heard of obstetric emergencies and as such would not be equipped to properly ensure adequate management of such. When asked the specific obstetric emergencies, the most popular emergency was postpartum hemorrhage. This is in line with the publications of Halidu and Salihu, 2017 and Adelaja and Taiwo, 2011. Out of the nine risk factors for developing obstetric emergencies included in the questionnaire, the most picked risk factors were age and infection, poor antenatal care and drugs and alcohol. Knowledge of the risk factors for the occurrence of obstetric emergencies ensures that the pregnant women who are at risk take extra precautions to prevent the occurrence as well as promptly attend to the emergencies if they eventually occur.

On the perception and attitude to obstetric emergencies, $66 \%$ agreed that obstetric emergencies can occur in any pregnant women however, only $58 \%$ agreed that the emergencies could occur in them. This is an indication that a good number of pregnant women still believe obstertric emergencies to be an abstract concept occurring in a selected population. This is also in line with the $25 \%$ who would not inform a physician but hope the obstetric emergency would go away. 
In comparison of the age groups and the occurrence of obstetric emergencies, the highest percentage occurred in the 21-30 (45\%) age group. This could be as a result of the greater population being within that age group.

\section{CONCLUSSION}

The best age group for pregnancy is between 20-30 years and in the study population, the pregnant women belonged mostly to this age group. The effective management of obstetric emergencies starts from adequate knowledge of the emergencies, the risk factors for the development of the emergencies and knowledge of the correct actions to take in the event of such emergencies occurring. In the study however, less than half of the study population knew what obstetric emergencies were and even less were aware of the risk factors for the development of emergencies and quite a number did not even believe that such conditions could occur in them.

There is therefore a need to adequately incorporate lectures on obstetric emergencies into the antenatal care routine in order to better equip pregnant women in managing them.

\section{REFERENCES}


Abalos E., Cuesta C., Grosso A. L., Chou D., and Say L., Global and Regional Estimates of Preeclampsia and Eclampsia: A systematic Review, European Journal of Obstetric Gynecology and Reproductive Biology, 170(1): 1-7.

Adelaja L. M., and Taiwo O. O., (2011), Maternal and Fetal Outcome of Obstertric Emergencies in a Tertiary Institution in South-western Nigeria, International Scholarly Research Notices, vol.2011, article ID 160932.

Ali S. K., Ali A.A., and Soomar S. M., (2019), Diagnosis and Management of Ectopic Pregnancy- A Basic View Through Literature, Critical Care Obstetrics and Gynecology, vol. 5 No.2:7.

Artal-Mittelmark Raul, (2019), Overview of High Risk Pregnancy, MSD Manual Proffesional Version.Accessed via https://www.msdmanuals.com/professional/gynecology-andobstetrics/high-risk-pregnancy

Artal-Mittelmark Raul, (2019), Risk Factors for Complications During Pregnancy, MSD Manual Proffesional Version.Accessed via https://www.msdmanuals.com/professional/gynecology-and-obstetrics/high-riskpregnancy/risk-factors-for-complications-during-pregnancy

Barr J., and Marugg L., (2019), Impact of Marriage on BirthOutcomes: Pregnancy Risk Assessment Monitoring System, Sage Journals.

Bellieni Carlo, (2016), The Best Age for Pregnancy and Undue Pressures, Journal of Family and Reproductive Health, vol. 10, No. 3.

Blomberg M., Tyberg R. B., Kholhede P., (2014), Impact of maternal age on obstertric and neonatal outcome with emphasis on primiparous adolescents and older women: a Swedish Medical birth register study, BMJ open, vol. 10

Chhabra S., (2017), Emergency obstetric care, essentialities for prevention of maternal/neonatal mortality/morbidity, Obstetrics and Gynecology International Journal, vol 8 issue 2.

English F.A., Kenny L.C., and McCarthy F.P., Risk Factors and Effective Management of Preeclampsia, Integrated Blood Pressure Control 8:7-12

Evensen A., Anderson J.M., and Fontaine P., (2017), Postpartum Hemorrhage: Prevention and Treatment, American Academy of Family Physicians 95(7): 442-449.

Ketema D. B., Tesema L., and Alebel A., (2020), Effects of Maternal Education on Birth Preparedness and Complication Readiness among Ethiopian Pregnant Women: a Systematic Review and Meta-analysis, BMC Pregnancy and Childbirth 20 149(2020) 
Lincetto O., Mothebesoane-Anoh S. Gomez P., and Munjanja S., Opportunities for African Newborn: Antenatal care. Pp 51-62

Micheal G. Ross, 2019, Eclampsia, Medscape. Accessed via: https://emedicine.medscape.com/article/253960-overview

Omo-Aghoja L. O., Aisien O.A,,Akuse J.T., Bergstrom S., and Okonofua F.E., (2010). Maternal mortality and emergency obstertric care in Benin City, South-south Nigeria. Journal of Clinical Medicine and Research. Vol. 2(4), pp 055-060.

Olonade O., Olawande T. I., Alabi O. J. and Imhonopi D., (2019), Maternal mortality and maternal health care in Nigeria: implications for socio-economic development, Open Access Macedonian Journal of Medical Sciences. 7(5), pp 849-855.

Osungbade K., and Ige O., (2011). Public Health Perspectives of Pre-eclampsia in Developing Countries: Implication for Health System Strengthening, Journal of Pregnancy, vol. 2011, Article ID 481095.

Paul Ashigbie, (2013), Postpartum Hemorrhage, Priority Medicines for Europe and the World; A Public Health Approach to Innovation,6.16-2.

Halidu G. S., and Salihu Z., (2017), Administration of Emergency Obstertric Care Services, Prevalence and Outcome in Nigeria: A Policy Dimension, FUDMA Economic and Development Review, vol. 1, Issue 1.

Singh A.S., Masuku M.B., (2014). Sampling Technique and determination of sample size in applied statistics research: An overview. International Journal of Economics, Commerce and Management, United Kingdom. II (11): 14

World Health Organization (WHO)., (2017). Managing Complications in Pregnancy and Childbirth: A guide for midwives and doctors. Second Edition. Section 1: Clinical principles, C-21-C25.

\section{APPENDIX}

1. Questionnaire 


\section{AWARENESS OF PREGNANT WOMEN REGISTERED WITH FEDERAL MEDICAL CENTRE, MAKURDI ON THE RISK FACTORS OF OBSTETRIC EMERGENCIES.}

\section{DEMOGRAPHICS}

1. Respondent Initials

2. Age: $15-20$

3. Marital status: single

4. Educational qualification: primary

5. Occupation: student
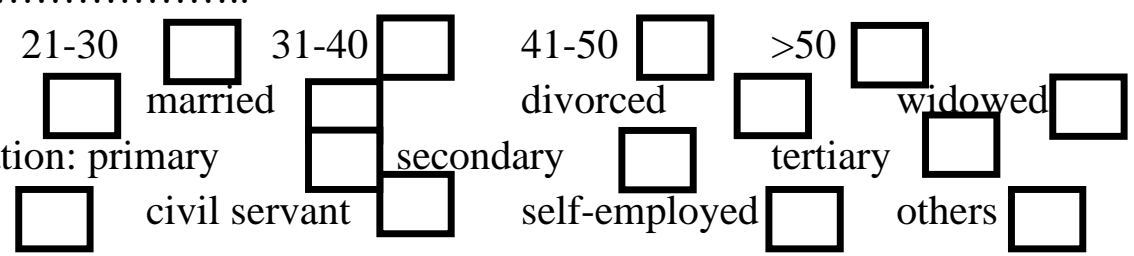

\section{KNOWLEDGE}

Please answer the following questions or tick the appropriate option.

1. Is this your first pregnancy?

Yes (move to question 3)

No (answer question 2)

2. Age at first pregnancy.

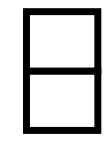

3. Do you know what obstetric emergencies are?

Yes

No

Not sure

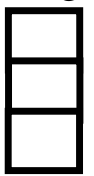

4. Have you heard of any of the following?

\begin{tabular}{|l|l|l|l|l|}
\hline S/N & & YES & NO & NOT SURE \\
\hline 1 & Postpartum hemorrhage & & & \\
\hline 2 & Pre-eclampsia & & & \\
\hline 3 & Eclampsia & & & \\
\hline 4 & Ectopic pregnancy & & & \\
\hline 5 & Abruptio placentae & & & \\
\hline 6 & Placenta previa & & & \\
\hline 7 & Septic abortion & & & \\
\hline 8 & Obstetric sepsis & & & \\
\hline 9 & Preterm labour & & & \\
\hline
\end{tabular}

5. Have you experienced any of the following?

\begin{tabular}{|l|l|l|l|l|}
\hline S/N & & YES & NO & NOT SURE \\
\hline 1 & Postpartum hemorrhage & & & \\
\hline 2 & Pre-eclampsia & & & \\
\hline 3 & Eclampsia & & & \\
\hline 4 & Ectopic pregnancy & & & \\
\hline 5 & Abruptio placentae & & & \\
\hline
\end{tabular}




\begin{tabular}{|l|l|l|l|l|}
\hline 6 & Placenta previa & & & \\
\hline 7 & Septic abortion & & & \\
\hline 8 & Obstetric sepsis & & & \\
\hline 9 & Preterm labour & & & \\
\hline
\end{tabular}

6. If the YES to any in 5. above, what symptoms did you experience? List as many as you can.

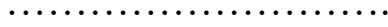

7. What was the outcome of management?

8. What are the risk factors for obstetric emergencies? Tick all the correct answers.

- Age

- Poor antenatal care

- Witchcraft

- Infections

- Drugs and alcohol

- Physical exercise

- Hypertension

- Sexual intercourse

- Diabetes

- Previous obstetric emergency

- Ignorance

- Others. Specify

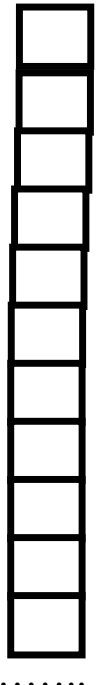

9. Do you have any risk of developing an obstetric emergency? If YES please state the risk factor (s).

10. What actions have you taken to prevent the occurrence of the emergency?

- Informed my physician

- Informed my pastor/clergyman

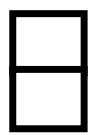


- Gone to the mountain for prayers

- Informed the nurses

- I'm hoping it does not occur

- God forbid! I'm covered by the blood of Jesus.

- Others. Please specify............................

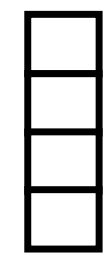

\section{ATTITUDE/PERCEPTION}

1. Obstetric emergencies can occur in any pregnant woman.

True

False

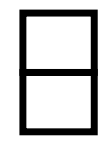

2. It's possible for me to develop an obstetric emergency

True

False

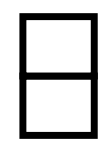

3. If I notice any unusual symptom that may be the occurrence of an obstetric emergency I would...(tick all that apply)

- Observe for some days before reporting to anyone.

- Inform my physician immediately.

- Inform my pastor/clergyman immediately.

- Pray fervently and hope it goes away.

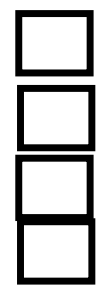

- Ignore the symptom and it would disappear. 